\author{
Mojca Smolej \\ Filozofska fakulteta, Ljubljana \\ DOI: 10.4312/SSJLK.57.11-20
}

\title{
Spolski vidiki slovenskega jezika
}

O spolu bodisi kot jezikovno sistemski kategoriji, družbeni kategoriji, literarno stereotipni kategoriji itn. je bilo v zadnjem času - mišljeno je obdobje zadnjih tridesetih let - povedanega in napisanega zelo veliko. $V$ prispevku bomo skušali na omenjeno problematiko pogledati z različnih zornih kotov. Dotaknili se bomo tako kontekstualizacije oseb ženskega in moškega spola, ki jo izpričujejo nekateri slovarji (npr. SSKJ), kot tudi slovnične obravnave spola predvsem v povezavi z inkluzivno teorijo in drugimi ravnmi jezikovnega sistema.

spol, kontekstualizacija, inkluzivna slovnica, feminizacija, ujemanje

Over the last thirty years, a great deal has been said about gender as a language system category, a social category, a literary stereotype, and so on. This contribution considers the issue from a number of different perspectives. It touches upon contextualisation of the person of male and female gender in certain dictionaries (e.g. SSKJ), as well as the grammatical treatment of gender, particularly in connection with inclusion theory and other levels of the language system.

gender, contextualisation, inclusive grammar, feminisation, concord

\section{Kontekstualizacija oseb ženskega in moškega spola}

S kontekstualizacijo oseb ženskega in moškega spola se je leta 2007 na jutranjem tečaju na 43. Seminarju slovenskega jezika, literature in kulture ukvarjal že Vojko Gorjanc. Ker je od takrat minilo že dobrih 14 let, bomo preverili, ali se je opis ženskega in moškega spola v izbranih slovarjih kakorkoli spremenil, dopolnil (npr. primerjava med SSKJ1 in SSKJ2). Omenjeni pregled bo le del našega dela, pri analizi pa bomo ostajali ves čas le na površini oziroma se bomo dotikali le možnih izhodišč.

Gorjanc (2007: 179) je po pregledu SSKJ1 prišel do (vsaj za tisti čas) pričakovanih zaključkov.

Veliko bolj zanimiva je analiza pojavljanja besed fant in dekle ter kontekstov, v katerih se v slovarju pojavljata. [...] Glede pripisovanja negativnih lastnosti lahko opazimo, da se dekletom pripisujejo večkrat glede na fizične lastnosti [...], fantom glede na njihove vedenjske lastnosti [...], ko pa gre za pripisovanje fizičnih lastnosti, te večkrat izpostavljajo fizično moč oz. pozitivne karakteristike. [...] Pri fantih tudi nikoli ne najdemo negativnih seksualnih karakteristik.

Zgledi rabe so torej izkazovali negativno kontekstualizacijo oseb ženskega spola (oziroma rabe besed dekle in ženska). Osredotočili se bomo na pregled besed dekle, ženska, fant, moški v SSKJ $2,{ }^{1}$ in sicer bomo delno pregledali rabo omenjenih besed v nekaterih zgledih. Vseh primerov

1 Druga, dopolnjena in deloma prenovljena izdaja SSKJ je izšla leta 2014. Prva izdaja (v petih zvezkih) je izhajala v letih 1970-1991. 
rabe oziroma zgledov, ki vsebujejo besedo dekle, je 1443, zgledov z besedo ženska 1486 , z besedo fant $1637, z$ besedo moški pa 1267. Iz vseh zgledov smo naključno izbrali nekaj primerov, na osnovi katerih lahko sklepamo na splošno kontekstualizacijo moških in ženskih oseb.

Zgledi za besedo dekle:

- dekle nežnih in bledikastih lic (bledikast) ${ }^{2}$

- dekle ga mami s svojo bohotnostjo (bohotnost)

- to dekle je kot bonbonček (bonbonček)

- dekle se oblači dostojno (dostojen)

- dekle je prava dobroživka (dobroživka)

- dekle je domišljavo (domišljav)

- njegovo dekle je res kebrček (kebrček)

- lišpavo dekle (lišpav)

- nedolžno dekle (nedolžen)

- nevedno dekle (neveden)

- dekle se ne pritakne knjige niti metle (pritakniti se)

- seksi dekle (seksi)

- dekle se je skurbalo (skurbati se)

- dekle ga je uročilo (uročiti)

- dekle živahnega vedenja (živahen)

Zgledi za besedo fant:

- do abotnosti naiven fant (abotnost)

- fant se boji samo očeta (bati se)

- fant je čisto butast (butast)

- fant je obdarjen z izredno dojemljivostjo (dojemljivost)

- postaven fant (fant)

- ta fant je pravo govedo (govedo)

- hecen fant (hecen)

- fant je izpridenec (izpridenec)

- preprost fant (preprost)

- mišičav in plečat fant (mišičav)

- fant ga je spet natolkel (natolči)

- živahen, neobvladljiv fant (neobvladljiv)

- bil je prikupen fant (prikupen)

- prevzeten fant (prevzeten)

- tih, sramežljiv fant (sramežljiv)

- ta fant je prava tutka (tutka)

2 V oklepaju so zapisane iztočnice. 
Po naključnem izpisu približno $1 \%$ primerov rabe besed dekle in fant se $v$ ospredju izrisuje predvsem paternalističen odnos do mladih oseb, kar pomeni, da je negativna kontekstualizacija vezana predvsem na kategorijo starosti oziroma na intelektualno zmožnost mladih ljudi (npr. nevedno dekle, fant je butast) in ne toliko spola. Negativna spolna konotacija je večinoma vezana na obe besedi oziroma spola: dekle se je skurbalo, fant pa je izpridenec. Glede na to, da bi lahko pregled zgledov z besedama fant in dekle povezali s pregovorom mladost je norost, čez vodo skače, kjer je most, predvidevamo, da tovrstne konotacije pri pregledih zgledov z besedama moški in ženska ne bo.

Zgledi za besedo ženska:

- aseksualna ženska (aseksualen)

- brezsramna ženska (brezsramen)

- čvekasta ženska (čvekast)

- fatalna ženska (fatalen)

- jalova ženska (jalov)

- izredno duhovita in lucidna ženska (luciden)

- noseča ženska (nositi, noseč)

- pocestna ženska (pocesten)

- polnoprsa ženska (polnoprs)

- med moškimi je bil rekorder tisti, ki mu je promilomat pokazal 3,79 promila alkohola v krvi, ženska rekorderka pa je napihala 2,22 promila (promilomat)

- ženska je ponekod še vedno sužnja moža (sužnja)

- trmasta in sitna ženska (trmast)

- ženska se vlačuga (vlačugati se)

- z njim ne vzdrži nobena ženska (vzdržati)

- nobena ženska ga ni zadovoljila (zadovoljiti)

Zgledi za besedo moški:

- biseksualen moški (biseksualen)

- feminilen moški (feminilen)

- kakšen moški pa si, da si tega ne upaš? (kakšen)

- ženske se pri delu bolj koncentrirajo kot moški (koncentrirati se)

- moški radi gledajo za dekleti v minicah (minica)

- okradel ga je mlajši moški (mlajši)

- bradat, lep, mlad moški (moški)

- nesimpatičen moški (nesimpatičen)

- v lokal se je opotekel pijan moški (opoteči se)

- prepotentni in impotentni moški (prepotenten)

- $v$ takih razmerah se moški poženščijo (poženščiti se)

- moški so gledali televizijo in srebljali pivo (srebljati)

- nekateri moški radi svinjajo (svinjati) 
- morda bi si moški drznili več, če ne bi bili stajlingi v modnih revijah tako očitno gejevsko obarvani (styling, SNB ${ }^{3}$ )

- ugrabil ga je zakrinkan moški (ugrabiti)

Če dekleta in fantje veljajo za nevedne ali celo butaste, je pri ženskah in moških podoba nekoliko drugačna. Negativna kontekstualizacija je pričakovano prisotna pri obeh, pri moških so izpostavljeni pijančevanje (npr. pijan moški; moški so srebljali pivo), kriminalna dejanja (npr. ugrabil ga je zakrinkan moški) in "poženščenost" oziroma »neustrezna" spolna usmerjenost (npr. v takih razmerah se moški poženščijo; [...] če ne bi bili stajlingi v modnih revijah tako očitno gejevsko obarvani). Pri ženskah je prav tako prisotna negativna kontekstualizacija spolne aktivnosti, le da tu ni izpostavljena spolna usmerjenost, pač pa predvsem "najstarejša «̌̌enska dejavnost in njena metaforizacija (npr. ženska se vlačuga; pocestna ženska), izpostavljeni pa sta tudi rodnost in ženski deli telesa (npr. jalova ženska; polnoprsa ženska).

Pri pregledu slovarskega gradiva bi se bilo dobro ustaviti tudi pri obeh slovarjih sinonimov (Sinonimni slovar slovenskega jezika in Slovar sopomenk sodobne slovenščine) in frazeološkem slovarju. Nabor sinonimov (in frazeološkega gradiva) namreč prav tako razkriva tip kontekstualizacije oseb ženskega in moškega spola.

\subsection{Tajnik ali tajnica}

Pregled slovarskega gradiva je zanimiv tudi zaradi poimenovanj nekaterih poklicev, npr. poklicev tajnik oziroma tajnica. O slednjem je bilo napisanega že zelo veliko. ${ }^{4} 22.5 .1997$ je bila v Uradnem listu objavljena Uredba o uvedbi in uporabi standardne klasifikacije poklicev, ${ }^{5} \mathrm{v}$ kateri je 44-krat zapisan poklic tajnika in za njim še tajnice (npr. tajnik/tajnica občine; republiški tajnik/ republiška tajnica za volitve; tajnik/tajnica društva; strojepisci/strojepiske, tajniki/tajnice ipd.). Iz pregleda vseh predvidenih poimenovanj poklicev tajnikov in tajnic je razbrati, da med pomenom besede tajnik in pomenom besede tajnica ni razlik (če odmislimo slovnično kategorijo spola). Pravkar napisano je zanimivo, saj je v času, ${ }^{6}$ ko nastaja pričujoči prispevek, na rektoratu Univerze v Ljubljani kot glavni tajnik (in ne kot tajnica) zaposlena ženska. ${ }^{7}$ Če besedi tajnik in tajnica pregle-

3 Slovar novejšega besedja.

4 V javni razpravi leta 1995 je Vera Kozmik opozorila tudi na problem poimenovanj oseb, njihovih funkcij in poklicev. Menila je, da problem sicer ni toliko v tem, "da poklici niso napisani v ženski obliki, ampak predvsem to, in to je diskriminacija, da je 73 določenih poklicev napisanih v ženski slovnični obliki« (Kozmik, Jeram 1995: 51). Za to, da se je zgodilo nekaj sprememb, je trajalo kar dolgo, hkrati pa do teh sprememb ni prišlo na vseh področjih. Tako danes na številnih spletnih straneh institucij, tudi izobraževalnih, še vedno beremo tajnik in ime in priimek ženske, ki zaseda to delovno mesto (Kranjc, Ožbot 2013: 236).

5 Gl. tudi Smernice za spolno občutljivo rabo jezika, 2018, Mojca Šauperl, Helena Dobrovoljc, Jasna Jeram, Maksimiljan Gulič.

6 3. 5. 2020.

7 Mihaela Bauman Podojsteršek je univerzitetna diplomirana ekonomistka. Svojo poslovno pot je začela leta $1986 \mathrm{v}$ gospodarstvu, in sicer kot svetovalka za finance in računovodstvo. Deset let kasneje je pot nadaljevala v javnem sektorju. $\mathrm{Na}$ takratnem ministrstvu za šolstvo je kot svetovalka ministra sedem let skrbela za načrtovanje in izvajanje proračuna ter financiranje javnih zavodov. Na Univerzi v Ljubljani se je več let ukvarjala z notranjo revizijo in večjimi investicijskimi projekti, bila je tudi pomočnica rektorja za finančno področje. Na mesto glavnega tajnika Univerze je bila s 1. 7. 2014 imenovana za šest let. (https://www.uni-lj.si/o_univerzi_v_ljubljani/organizacija) 
damo še v SSKJ2 in gesli primerjamo, vidimo, da je med njima precejšnja pomenska razlika, ki je najprej prisotna v sami razlagi 1. pomena, nato pa v polnosti pri 2. pomenu.

tájnica -e ž (â)

1. ženska, ki opravlja administrativne, organizacijske, tehnične posle: narekovati pismo tajnici; zaposlena je kot tajnica; tajnica direktorja / tajnica režije ki med snemanjem zapisuje tehnične, organizacijske podatke, režiserjeve opombe

2. naprava, storitev, ki ob telefonskem klicu predvaja posneto sporočilo in shranjuje sporočila klicateljev: oglasila se je avtomatska tajnica / telefonska tajnica

tájnik -a m (â)

1. kdor opravlja administrativne, organizacijske, tehnične posle: dati navodila tajniku; tajnik šole; dela in naloge tajnika / osebni tajnik / občinski tajnik nekdaj kdor opravlja pisarniške posle na občini; tajnik režije ki med snemanjem zapisuje tehnične in organizacijske podatke, režiserjeve opombe

2. visok funkcionar kake organizacije, telesa: izvoliti tajnika; glavni tajnik; predsednik in tajnik

Medtem ko je tajnik opredeljen tudi kot visok funkcionar (2. pomen), ostaja tajnica le na ravni opravljanja administrativnih poslov (1. pomen pri tajnici in tajniku). Zaključimo lahko, da čeprav uradna uredba odpravlja razlikovanje med tajnikom in tajnico, ta še naprej obstaja in ostaja. Temelji pa izključno na slovnični kategoriji spola.

\section{Inkluzivna slovnica ${ }^{8}$}

Iz slovarske ravni bomo prešli na slovnično, čeprav sta obe ravni neobhodno tesno povezani in se medsebojno vključujeta, kar bo razvidno tudi iz same obravnave. Predstavili bomo (in hkrati skušali kritično opredeliti) slovnične postopke jezikovne feminizacije, ki so vezani tako na govorjeni kot pisni jezik, hkrati pa se izogibajo rabi moškega spola kot generičnega. Temelj inkluzivne slovnice sta tako leksikalna in skladenjska feminizacija. Leksikalna feminizacija pomeni tvorjenje ženskih oblik besed (besedotvorje), skladenjska pa feminizacijo besede znotraj besedne zveze (npr. ujemanje).

\subsection{Leksikalna feminizacija}

Ogledali si bomo 7 različnih vrst leksikalne feminizacije: (1) rabo historične oblike, (2) rabo sodobnih besedotvornih zakonitosti slovenskega jezika, (3) ozir na splošno oziroma ljudsko rabo, (4) zamenjavo samostalnikov, (5) rabo tujk ali prevzetih besed, feminiziranih po besedotvornih postopkih izvornega jezika, (6) rabo neologizmov in nove grafije, (7) radikalno feminizacijo.

V prispevku se bomo zaradi tehničnih omejitev ustavili le pri treh.

8 Drugi del pričujočega prispevka izhaja iz prispevka Mojce Smolej, Anormativizem in dileme inkluzivne slovnice (2019). 
(1) Raba sodobnih besedotvornih zakonitosti slovenskega jezika je najpogostejši postopek za feminizacijo do zdaj, npr.: zidar $\rightarrow$ zidarka (SSKJ2), rudar $\rightarrow$ rudarka*, gozdar $\rightarrow$ gozdarka (SSKJ2), dekan $\rightarrow$ dekanja, dekanka, dekanica (SSKJ2). Kot pomanjkljivost se lahko kaže večbesednost, pri čemer besede tekmujejo za prevlado. Samo tvorjenje je nezahtevno, saj se upoštevajo besedotvorni postopki, tipični za slovenski jezik.

(2) Raba neologizmov in nove grafije pozna več postopkov:

a) tvorjenje obojespolne besede z izrabo že obstoječe, ki največkrat izraža srednji slovnični spol, npr.: študentje + študentke $\rightarrow$ študentstvo; profesorji + profesorice $\rightarrow$ profesorstvo; deklice in dečki $\rightarrow$ otroci $^{\star}$ (je že zaznamovan z moškim spolom) ali otroštvo* (ima že svoj primarni pomen in lahko vnaša nejasnost) ali predšolske in šolske osebe (je že zaznamovan z ženskim spolom in spolno ni nevtralen)*; nujno je še dodati, da obojespolne besede v srednjem slovničnem spolu mnogokrat niso slogovno enakovredne enospolnim besedam.

b) tvorjenje obojespolne besede z združitvijo morfemov obeh besed, npr.: brat + sestra $\rightarrow$ brastra (se ne zmore izogniti slovničnemu spolu); hči + sin $\rightarrow$ hčin (se ne zmore izogniti slovničnemu spolu, čeprav zaobjema oba prvotna samostalnika).

c) raba posebnih grafičnih znamenj, npr. podčrtaja: študent_ka, predsednik_ca (otežuje berljivost in razumevanje). Raba neologizmov in nove grafije skuša poiskati nevtralen izraz, ki je največkrat srednjega spola, vendar pa prav zaradi rabe različnih grafičnih znamenj (npr. podčrtaja) otežuje berljivost in razumevanje.

(3) Radikalna feminizacija temelji izključno na rabi ženskega spola, ki vključuje tudi moške osebe, npr. Študentke morajo za vpis v višji letnik doseči najmanj 60 KT.

Žal se pomanjkljivost pri večini postopkov kaže prav na ravni razumljivosti oziroma koherence, občasno pa tudi na ravni prezahtevne ali preobtežene tvorjenosti zaradi doslednega upoštevanja rabe vseh spolov (npr. sklep o zaposlitvi vršilca dolžnosti ravnatelja/vršilca dolžnosti ravnateljice/ vršilke dolžnosti ravnateljice/vršilke dolžnosti ravnatelja), kar še dodatno otežuje koherenco samega besedila. Problem radikalne feminizacije je njen nasprotni učinek (raba izključno enega spola). Če bi hoteli biti torej skrajno dosledni pri zahtevah feminizacije, bi morali poseči po postopkih tvorjenja novega spola, ki bi zaobjemal vse spole, oziroma v nespolno rabo jezika. To bi zagotovo pomenilo precejšen poseg v sistem slovenskega jezika. Skušali bomo premisliti tudi o vseh možnih postopkih, ki bi pravkar napisano vsaj delno smiselno realiziralo.

\subsection{Skladenjska feminizacija}

V okviru skladenjske feminizacije je možnih 7 različnih postopkov. Vezani so predvsem na načine izražanja skladenjskih razmerij (ujemanje). Ker so že sami primeri dovolj povedni, postopkov ne bomo natančneje pojasnjevali. 
Tabela 1: Skladenjska feminizacija

\begin{tabular}{|l|l|}
\hline Vrsta skladenjske feminizacije & Primer \\
\hline Ujemanje po bližini & $\begin{array}{l}\text { Dijaki in dijakinje so končale s poukom. } \\
\text { Dijakinje in dijaki so končali s poukom. }\end{array}$ \\
\hline Alternacija spolov & $\begin{array}{l}\text { Dijaki so bili veseli konca pouka, saj se bodo lahko med prazniki } \\
\text { končno odpočile in vsaj za nekaj časa pozabili na šolske obveznosti. }\end{array}$ \\
\hline Dvojnica & Dijaki/dijakinje so končali/končale s poukom. \\
\hline Ženski spol kot generični & Dijakinje so končale s poukom. \\
\hline Raba večinskega spola & Se ravna glede na število predstavnikov posameznega spola. \\
\hline Vezana grafija & $\begin{array}{l}\text { Možnih je veliko različnih grafij, npr.: } \\
- \text { Dijaki_nje so končali_e s poukom. } \\
\text { - DijakiNJE so končaliE s poukom. } \\
\text { - Dijaki+ so končali+ s poukom. } \\
\text { - Dijakinje- so končale- s poukom. } \\
\text { - Dijaki^so končali^s poukom itn. }\end{array}$ \\
\hline Enospolna (skupnospolna) raba & Dijaštvo je končalo s poukom. \\
\hline
\end{tabular}

\section{Ujemanje med osebkom in povedkom}

V drugem poglavju je bila kategorija ujemanja omenjena predvsem na ravni inkluzivne slovnice (oziroma radikalne feminizacije). V nadaljevanju bomo ujemanje analizirali tudi s stališča načina izražanja podrednega skladenjskega razmerja med osebkom in povedkom oziroma povedkovim določilom, in sicer v primerih, ki niso problematični v okviru »feminizacije«, pač pa izključno na ravni slovničnega izražanja kategorije ujemanja. Izpustili bomo torej primere, kot so: a) Ana in Janez sta se sprehajala/sta se sprehajali; b) Ana se je sprehajala z Janezom; c) Janez se je sprehajal z Ano itn. Zanimali nas bodo primeri, kot sta: a) Moja največja ljubezen je bil klavir oziroma b) Moja največja ljubezen je bila klavir. ${ }^{9}$

Slovenska slovnica Jožeta Toporišiča tovrstnih primerov ne obravnava. Obravnava le primere, pri katerih raba kategorije spola ni problematična.

Preden se podrobneje pomudimo ob povedku, poglejmo definicijo osebka s stališča sklona. Rekli smo, da je osebek tisti stavčni člen, ki je v imenovalniku kakor tudi povedkovo določilo, kot npr. v stavku Tomaž je otrok. Kateri imenovalnik je tu osebek in kateri določilo povedka? Na to vprašanje dobimo odgovor tako, da zamenjujemo bodisi prvi bodisi drugi samostalnik s samostalnikom katerega drugega spola. Če se pri tem mora spremeniti spol glagola, imamo opravka z osebkovim samostalnikom, sicer s povedkovim. Prim.: Tomaž je bil otrok proti Ivanka je bila otrok. [...] V primerih kot Tomaž je bil otrok ali Tomaž je bil sirota ali Tomaž je bil strašilo nam nespremenjena spolska značilnost glagola pove, da so imenovalniki otrok, sirota

9 Raziskavo je opravila Janja Ribič v svojem magistrskem delu Ujemanje med povedkom in osebkom v kopulativnih stavkih pod mentorstvom Mojce Smolej in Polone Gantar (2018, Filozofska fakulteta, Oddelek za slovenistiko). Del raziskav je bil predhodno objavljen v: Ribič 2016. 
in strašilo povedkovi. Spol povedkovega samostalnika namreč ne more vplivati na spol povedkovega glagola. (Toporišič 1982: 158)

Primeri, ki jih navaja Toporišič, so jasni, saj je v vseh samostalnikih v funkciji osebka izražena kategorija živosti. Primeri, v katerih je izražena kategorija neživosti, v različnih korpusih izpričujejo nedosledno rabo. Pri nekaterih je osebek tisti, ki narekuje spol in število, pri drugih pa je nasprotno povedkovo določilo tisto, ki prevzema vlogo nadrednega člena. Ogledali si bomo nekaj tovrstnih primerov. ${ }^{10}$

a) Zveza edninskega samostalnika (ali edninske samostalniške besedne zveze) v vlogi osebka $z$ edninskim samostalnikom (ali edninsko besedno zvezo) v vlogi povedkovega določila z izraženo kategorijo neživosti;

- Problem je bil slabša prodaja telefonov. : Velik problem je bila smučarska oprema.

- Pogoj je bil znanje angleškega jezika. : Osnovni pogoj je bilo znanje kitajščine.

- Moje vodilo je bilo kakovost. : Moje vodilo je bila vedno iskrenost.

- Njena prva ljubezen je bila klavir. : Njena prva ljubezen je bil klavir.

- Največja težava je bila pomanjkanje motivacije. : Največja težava je bilo finančno stanje.

V navedenih primerih ( $v$ vseh je izražena kategorija neživosti) smo izpostavili skoraj vse možne kombinacije po spolu: moški spol (osebek) - ženski spol (pov. določilo), moški spol (osebek) srednji spol (pov. določilo), srednji spol (osebek) - ženski spol (pov. določilo), ženski spol (osebek) - moški spol (pov. določilo), ženski spol (osebek) - srednji spol (pov. določilo). Kot je razvidno, prevzemata vlogo vodilnega člena tako osebek kot povedkovo določilo. V analizo primerov bi morali vključiti tudi širšo besediloslovno (diskurzivno) analizo (kontekst), ki bi temeljila na zakonitostih členitve po aktualnosti. Predvidevamo, da nam bi vsaj delno odkrila prevladujoči element, ki vpliva na prevzem vloge nadrednega člena.

b) Zveza edninskega samostalnika (ali edninske samostalniške besedne zveze) v vlogi osebka z edninskim samostalnikom (ali edninsko besedno zvezo) v vlogi povedkovega določila z izraženo kategorijo živosti oziroma človeškosti;

Vsaka četrta smrtna žrtev je bila pešec. : Druga žrtev je bil njen soprog, ki se je obesil.
: Vsaka stota žrtev je bil otrok.
: Nerešljiva uganka je bil Luka Modrić.
/
: Njihova prva misel je bil arhitekt R. Vasquez.
: Največja zvezda je bil pianist Bojan Gorišek.

V primerih, kjer ima samostalniška besedna zveza oziroma samostalnik, ki stoji za osebno glagolsko obliko, podspol človeškosti, lahko vidimo, da največkrat vlogo nadrednega člena prevzame

10 Pri primerih bomo izhajali iz magistrskega dela Janje Ribič (2018). V delu je tudi nadrobno opisan metodološki pristop $k$ analizi obravnavane problematike. 
prav povedkovo določilo oziroma tisti element, ki izraža kategorijo človeškosti. Povedkova vez se ujema s samostalniško besedno zvezo oziroma s samostalnikom, ki ima podspol človeškosti.

c) Zveza edninske samostalniške besedne zveze oziroma edninskega samostalnika z needninsko samostalniško besedno zvezo oziroma $z$ needninskim samostalnikom v vlogi povedkovega določila; Toporišič večkrat zapiše, da se povedkova vez v primeru, da je povedkovo določilo v drugem številu kot osebek, ujema s povedkovim določilom, in ne osebkom.

Navadno je osebek tisti, ki ujema ves povedek, če pa je povedek zložen in povedkovo določilo v drugem številu kakor osebek, se vez ujema s povedkovim določilom: To mesto so Brežice [...] (Toporišič 1992: 338)

Zanimivo je, da pregled rabe v korpusu Gigafida navedene trditve ne podpira popolnoma.

V korpusu Gigafida lahko najdemo veliko primerov kopulativnih stavkov, kjer je samostalniška besedna zveza oziroma samostalnik na začetku stavka v ednini, samostalniška besedna zveza oziroma samostalnik, ki stoji za osebno glagolsko obliko, pa v dvojini ali v množini. Toporišič (2004), Kunst-Gnamuš (1993) ter Orešnik in Orešnik (2007) trdijo, da se v teh primerih povedkova vez ujema s povedkovim določilom (torej bi naj obliko povedkove vezi narekovala samostalniška besedna zveza oziroma samostalnik, ki stoji za osebno glagolsko obliko), česar raba v korpusu Gigafida ne potrdi popolnoma. (Ribič 2016: 144)

Ogledali si bomo nekaj primerov, in sicer razporejenih glede na različne zveze po spolu, številu ali kategoriji živosti.

- Tema je bila morski motivi.

- Moje osnovno vodilo je bilo nespremenjena harmonija in melodija narodnih pesmi.

- Rezultat je bil manjše razlivanje in ostrejše tiskanje na navaden papir.

- Rezultat so bili veliki premiki cen na nepremičninskem trgu.

- Predmet pogovora so tudi zahteve avtoprevoznikov iz junija letos.

- Moja prva ljubezen so bili Beatli.

- Velika uganka so Avstralci.

- Rdeča nit pogovora sta seveda Michael Schumacher in Fernando Alonso.

Prvi primer izrazito izstopa iz predvidene normativne rabe, po kateri naj bi se vez ujemala s povedkovim določilom, kadar je ta $v$ drugem številu (npr. dvojini ali množini) kot osebek (ki je v ednini). Korpus Gigafida vsekakor kaže, da so tovrstni primeri redki.

Drugi in tretji primer vsebujeta zloženo povedkovo določilo oziroma priredno zvezo besed v vlogi povedkovega določila, zato lahko le pogojno trdimo, da se vez ne ujema s povedkovim določilom.

$\checkmark$ četrtem in petem primeru sta kopulativna stavka, $v$ katerih je osebek (neživo) v ednini, povedkovo določilo (s kategorijo neživo) pa v množini. V obeh se, tako kot predvideva Slovenska slovnica, vez ujema s povedkovim določilom.

V zadnjih treh primerih vlogo povedkovega določila opravljajo samostalniške besedne zveze oziroma samostalniki v množini s podspolom človeškosti, zato obliko povedkove vezi ne narekujejo samostalniške besedne zveze oziroma samostalniki v vlogi osebka, pač pa v vlogi povedkovega 
določila. Enako se je pokazalo tudi v primerih, pri katerih sta tako osebek kot povedkovo določilo $\checkmark$ ednini.

\section{Sklep}

$\mathrm{Na}$ spol v jeziku smo pogledali zelo omejeno in še to le z nekaterih zornih kotov. Kot sta zapisali že S. Kranjc in M. Ožbot (2013: 233), so študije jezika in spola tema, ki je po eni strani izjemno kompleksna, zato se prepleta skozi različna znanstvena področja, od jezikoslovja do psihologije in sociologije, po drugi pa posega na izredno občutljivo področje družbeno-kulturnih in etičnih norm.

\section{Viri in literatura}

GORJANC, Vojko, 2007: Kontekstualizacija oseb ženskega in moškega spola v slovenskih tiskanih medijih. Irena Novak Popov (ur.): Stereotipi v slovenskem jeziku, literaturi in kulturi. 43. SSJLK. Ljubljana: Center za slovenščino kot drugi/ tuji jezik pri Oddelku za slovenistiko.

KOZMIK VODUŠEK, Vera, JERAM, Jasna, 1995: Neseksistična raba jezika. Ljubljana: Vlada Republike Slovenije, Urad za žensko politiko.

KRANJC, Simona, OŽBOT Martina, 2013: Vloga spolno občutljivega jezika v slovenščini, angleščini in italijanščini. Andreja Žele (ur.): Družbena funkcijskost jezika (vidiki, merila, opredelitve). Obdobja 32. Ljubljana: Znanstvena založba Filozofske fakultete.

KUNST-GNAMUŠ, Olga, 1989: Težave s stavčnočlenskim razločevanjem zaradi oblikovnega sovpadanja pomenskih in sklonskih razlik. Jezik in slovstvo XXXV/1-2. 15-24.

KUNST-GNAMUŠ, Olga, 1993: Slovnična zgradba in vloga stavkov s pomensko podstavo SZ1 biti SZ2. Jezik in slovstvo XXXVIII/7-8. 267-280.

OREŠNIK, Varja, OREŠNIK, Janez, 2007: Povedkovo določilo v naravni skladnji slovenščine. Jezikoslovni zapiski XII/1-2. 103-116.

RIBIČ, Janja, 2016: Ujemanje med povedkom in osebkom v kopulativnih stavkih. Jezik in slovstvo LXI/2. $140-147$.

RIBIČ, Janja, 2018: Vidiki ujemanja v kopulativnih stavkih v slovenščini in angleščini. Magistrsko delo. Ljubljana: Filozofska fakulteta, Oddelek za slovenistiko.

Slovar slovenskega knjižnega jezika [= SSKJ]. www.fran.si

SMOLEJ, Mojca, 2019: Anormativizem in dileme inkluzivne slovnice. Slavistična revija LXVII/2. 179-188.

VIDOVIČ MUHA, Ada, 2019: Spol - jezikovni sistem in ideologija. Slavistična revija LXVII/2. 127-137.

TOPORIŠIČ, Jože, 1982: Nova slovenska skladnja. Ljubljana: DZS.

TOPORIŠIČ, Jože, 2004: Slovenska slovnica. Maribor: Obzorja.

ZUPAN SOSIČ, Alojzija, 2007: Moški je glava in ženska srce - spolni stereotipi. Irena Novak Popov (ur.): Stereotipi v slovenskem jeziku, literaturi in kulturi. 43. SSJLK. Ljubljana: Center za slovenščino kot drugi/tuji jezik pri Oddelku za slovenistiko. 181-193. 